\title{
Scientific and practical foundations and business processes for the sustainable development of Smart City
}

\author{
Inna Krasovskaya ${ }^{1, *}$, Elena Schislyaeva ${ }^{1}$, and Felix Shamrai ${ }^{1}$ \\ ${ }^{1}$ St. Petersburg State Marine University, St. Petersburg, Russia
}

\begin{abstract}
The article investigates scientific and practical issues of transport logistics; the conceptual and methodological mechanisms of formation of the "Smart City" strategy are considered and its main business processes are interpreted; the author's description of the Internet of Things as a high-tech network of deterministic mechanisms, logistic algorithms, business processes and technical and technological devices, interconnected with each other and with the external socio-economic environment is presented; the international experience of the formation and functioning of transport and logistics business processes of "smart cities" was critically rethought; reducing costs, ensuring socio-economic growth and sustainability, while improving the quality of services and the life of citizens, are justified as fundamental tasks of smart city projects; studied the socio-economic objectives of the Smart City of St. Petersburg project, in particular, the formation of a list of measures to optimize business processes, the creation of an external economic environment that would facilitate the attraction of non-budgetary funding sources for the implementation of projects, the development of a methodology for monitoring indicators of socio-economic development and territorial planning of St. Petersburg; identified the main socio-economic advantages of the introduction of smart parking in relation to the infrastructures of smart cities and their residents; empirically confirmed the effectiveness of the implementation of an intelligent parking management system based on the "Internet of Things" technology in the social and economic conditions of St. Petersburg; the characteristic of transport and logistics advantages of the strategy "Smart city of St. Petersburg" is provided.
\end{abstract}

\section{Introduction}

The main purpose of the article is to study the theoretical and practical aspects of the development strategy of "smart cities", analyze the most important business processes, interpret transport logistics, in a wide epistemological context, and the logistics of passenger transportation, in particular, as well as study the Internet of Things, its main tools and information - communication technologies, in relation to the peculiarities of the formation and functioning of a modern "smart city", which argues the relevance of the topic

\footnotetext{
*Corresponding author: krasovskaya_inna@list.ru
} 
of publication, on the one hand, and fully confirms the timeliness and relevance of the chosen scientific direction, on the other.

Transport logistics is a priority component and, at the same time, the socio-economic imperative of managing modern business processes, which, as the main attributes, imply the delivery of resource and raw materials, the transportation of commodity masses, an assessment of economic efficiency, as well as a reduction in financial, investment, labor and time costs [1].

The logistics of passenger transportation as structural components and business processes involves planning, forecasting, management, monitoring and assessing the economic efficiency of passenger flows and vehicles serving them, logistics facilities and transportation algorithms in transport systems of smart cities.

The fundamental conceptual and theoretical tool and strategically significant practical and applied toolkit for studying the logistics of passenger transportation is a systematic method that allows you to optimize multifactorial transport business processes in a wide cognitive content, as well as rationalizing and increasing the economic efficiency of passenger transport systems in smart cities, in particular [2-4].

In integrated computational and analytical studies of the most important structural components of passenger transport systems in cities, traffic control devices, dispatch services, transport networks and the population, transport enterprises and management are most widely used [5]. In addition, the passenger transport systems as an active component imply the collectives of people and the population of the "Smart City".

The smart city development strategy is based on the large-scale use of information and communication technologies and business processes. The main instrument for the functioning of information and communication technologies in a smart city is the internet of things.

\section{Materials and Methods}

In modern conditions, two methods have become widespread, or, in other words, conceptual-theoretical and practical-applied mechanisms for the formation of the Smart City strategy: one involving the creation and functioning of a smart city from the ground up, or focused on the use of structural components of the strategy in existing territorially localized spaces modern cities [6-8].

The first option for the development of business processes of the Smart City strategy took place in Songdo (South Korea), which is planned to be completed by 2025, and which is currently fully equipped with science-intensive and high-tech equipment (sensors and sensors) operating within a single business process and aggregating factual information about road congestion, energy consumption, noise effect, the level of technogenic pollution of the air basin and other anthropogenic factors $[6,9]$. Songdo's "smart city" is focused on public transport, presenting an extremely comfortable environmentally friendly modern metropolis.

Regarding the second option for the development of business processes of the Smart City strategy, it should be noted that its fundamental structural components are used to one degree or another by almost all states of the world community without exception.

American IT-portal Techrepublic differentiated the most important technical and economic business processes for the development of the modern Smart City strategy [7]:

1. smart solutions used in transport infrastructure optimization processes;

2. smart parking lots, adapted to the purpose of timely informing about difficult traffic and setting the task of determining the time of arrival of the vehicle;

3. smart mobility / smart logistics, designed to form mechanisms for the transportation of passengers, logistics of goods, etc.; 
4. big data for residents of a smart city, focused on providing timely factual information to citizens, which allows you to significantly save time on standard registration procedures, queues, etc.;

5. smart infrastructure, which serves as the economic and technological basis for the management of urban business processes;

6. the Internet of Things, the main purpose of which is to create conditions for the largescale use of sensors and analytical "beacons" that interpret and critically rethink information and, thereby, optimize the territorially localized spaces of modern smart cities.

The Internet of Things is a high-tech network of deterministic mechanisms, logistic algorithms, business processes and technical and technological devices, interconnected with each other and with the external socio-economic environment.

The Internet of Things, acting as an innovative communication infrastructure of a "smart city", guarantees the achievement of standardized, easy-to-use and highly costeffective access to social services, transport and logistics business system, security system in public places, etc.

The Internet of Things is aimed to integrate the aforementioned six business processes of smart city development and achieve an optimized coherent socio-economic system.

Scientific and practical problems of the development of the digital economy, the formation and functioning of smart cities, increasing the efficiency of transport logistics and Internet of Things are given attention in the studies of Russian and foreign scientists [10-14].

\section{Results}

In the context of the processes of globalization, the development of digital technologies and the integration of the world economy, the study of international experience in the formation and functioning of transport and logistics business processes of "smart cities" is of scientific and practical interest.

For example, in Helsinki, an interactive map has become widespread, which in real time characterizes the movement of vehicles around the city and, at the same time, searches for optimal parking spots [6].

The economic effect of transport and logistics business processes is obvious: the fuel consumption regressed by $5 \%$, the productivity of drivers increased significantly (by 15 $20 \%$ ), the degree of passenger satisfaction increased by $7-10 \%$.

In Amsterdam, in order to increase the economic efficiency of business processes and the timely resolution of transport and logistics problems, centers of intellectual work have been formed and are operating, where it is possible to use innovative information and communication technologies, while having unlimited access to the road system and public transport.

Business processes for renting a car for citizens are developing intensively. For example, the Car2Go system operates in Washington, Vancouver, Berlin, Hamburg, Vienna, Amsterdam and other cities [14].

The processes of collective use of vehicles in Paris are no less active [15]. Snips Company has offered a version of the application adapted for the socio-economic conditions of Paris, informing at what hours the maximum concentration of citizens is expected at different points of transport, which makes it possible to timely destroy the problem of their congestion by using alternative means of transportation.

In addition, the Snips Company has developed a version of the application for New York, which predicts the number of free parking spaces at a given time on a specific street. 
In Seoul [11], more than a hundred transport stops are equipped with terminals that communicate wirelessly with thousands of buses. The buses are equipped with modems for wireless internet and GPS receivers.

As a result, the passenger at the stop sees on a special screen not only the bus schedule of a particular route, but also information about its actual movement, difficulties, traffic accidents on the route, etc. In addition, all information is available online.

By order of the Boston City Administration (USA), a special application for Street Bump smartphones has been developed [9]. The application uses accelerometers and GPS built into modern devices. The driver can download the application to his smartphone, pin it to the dashboard and turn it on. If the car hits a pothole with a wheel, Street Bump records this, determines the coordinates of the place using GPS, and sends the report directly to the utility server.

In Los Angeles, in search of parking, cars make 38 round-the-world journeys a year, using 213 thousand liters of fuel and emitting 730 tons of carbon dioxide into the atmosphere. In central Stockholm, an intelligent, cost-effective business transport management system has helped reduce congestion by $20 \%$.

The scientific novelty of the research lies in the argumentation of the fact that Smart parking, presented on the graph of the business process (figure 1), is an innovative example of the M2M system (machine-to-machine interaction). M2M is the generic name for technologies that allow machines to exchange information with each other, or transfer it unilaterally. The overall goal of such an M2M system is to optimize business processes.

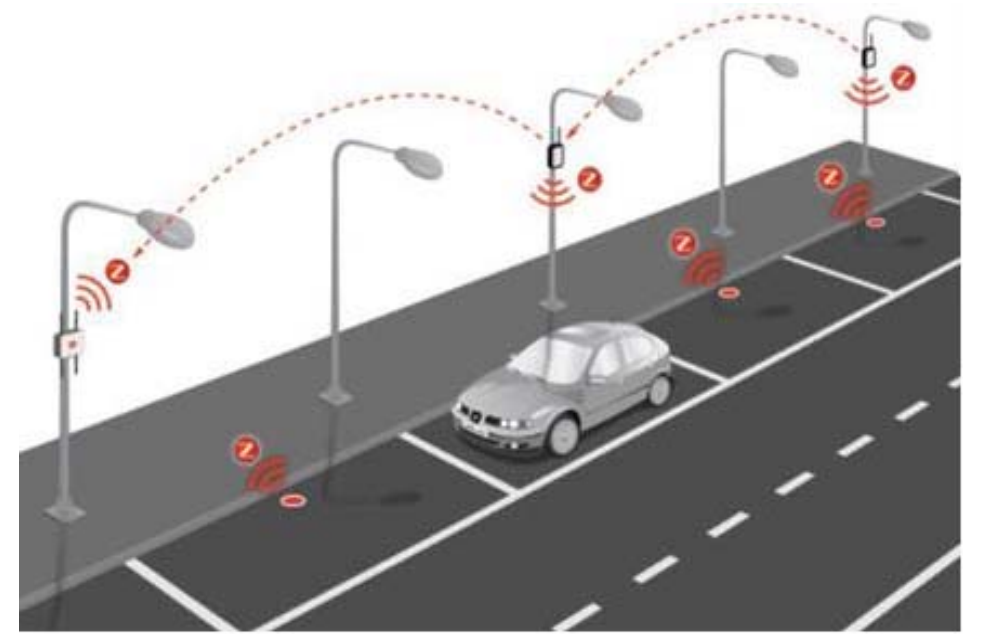

Fig. 1. Graphical interpretation of the smart parking business process [21].

In the most economically developed cities of almost all states of the world community, without exception, smart city solutions are currently being used quite actively, for example, in St. Petersburg, where some traffic flows are regulated by smart traffic light control, calculation of the time of arrival of public transport, integration of electronic queues in government agencies and other modern business processes [16].

\section{Discussion}

At present, active scientific and practical polemics are generated by the issues of the formation and functioning of "Smart Cities", in a broad cognitive perspective, in connection with which a search is underway for design practical and applied solutions that take into account the specifics and socio-economic features of the development of St. Petersburg as 
an outpost the Russian economy, on the one hand, and the planet's smart urban agglomeration, on the other.

The Smart City Saint Petersburg project is a complex of measures aimed at modern high quality economically efficient urban management, social and economic development and territorial planning of Saint Petersburg.

The goal of the Smart City St. Petersburg Project is to create a unified information space, a repository of structured data in the form of entered and calculated indicators of a unified nature, the use of which is expected in industry-specific automated business systems.

The creation of a data warehouse will ensure the consistency of data sources on the socio-economic and spatial development of the city, eliminate duplication of information and functionality of various information systems and databases used by various authorities.

The main socio-economic objectives of the Smart City St. Petersburg project are as follows:

1. Formation of a list of measures to optimize business processes and mechanisms for making scientifically and economically effective decisions, as well as monitoring their implementation;

2. Creation of an external economic environment conducive to attracting extra-budgetary sources of financing for the implementation of projects;

3. Development of a methodology for monitoring indicators of socio-economic development and territorial planning of St. Petersburg;

4. Formation of a business-system for scenario forecasting and modeling capabilities for social, economic development and territorial planning of St. Petersburg.

The following economic and social effects are expected from the implementation of the Smart City of St. Petersburg project: an increase in the revenue side of the city budget; increasing the economic efficiency of costs; optimization of socio-economic development processes; increasing the investment attractiveness of the city; increasing the attractiveness and quality of provided transport, communal, medical, educational and cultural services; increasing the attractiveness of the city's business environment and the quality of life of citizens.

The most important scientific and practical problem, in the context of the above, is to recognize the fact that due to the increase in the number of car owners, it is permanently difficult to find a parking place in densely populated areas of the city [17].

Finding an accessible place often takes up potentially productive time for city dwellers, increases the number of cars passing on highways, and creates congestion, traffic jams, provoking new infrastructure problems.

In order to optimize the business process of finding comfortable parking places by residents of St. Petersburg, assistive technologies, the Internet of Things, are being actively introduced.

Smart parking is a dedicated parking space that uses sensors and state-of-the-art technology to cost-effectively locate parking spaces, provide security, and automate parking. The volume of the world market "Smart city" in 2020 will amount to \$ 124 billion, which is $18.9 \%$ more than in 2019. Such data testifies to the readiness of the governments of virtually all states of the world community, without exception, to invest in the development of smart city technologies [18].

Many smart cities of the planet currently have significant empirical information collected through the use of sensors located in the external urban environment to monitor traffic, measure the noise effect, and air pollution with various man-made inputs [2-4]. The obtained data are actively used by city authorities to improve the quality of life of urban residents. 
The realm of smart cities includes artificial intelligence technologies, self-driving cars, smart street lighting and smart parking infrastructure. Smart city projects are primarily aimed at solving fundamental problems for cities: reducing costs, ensuring socio-economic growth and sustainability, while improving the quality of services and life of citizens.

The economic efficiency of the implementation of business projects of "smart cities" is largely determined by human resources. Timely solutions to smart city development challenges depend on good governance, long-term investment and human participation.

Smart city projects are focused on solving the transport and logistics problems of modern megacities. Digitalization and innovative technologies can optimize the organization and management of traffic flows and parking in cities, while creating new business opportunities.

The main task of smart parking is to help the driver quickly find a free space with the most convenient location for him. For this, sensors, LPWAN and automation are most often used.

The sensors can be either hinged (for guarding and monitoring the car), and groundbased - for registering objects that are in a parking space.

Another area is the development and implementation of automated parking lots (most often multi-level), in which the actions of drivers are minimized [19]. For example, a driver drives into a special platform and gets out of the car, and the platform itself transfers the car to a reserved or free seat, informing the driver of its number. To get the car back, the owner needs to $\log$ in and pay through the scoreboard or mobile application, after which the platform will lower the car to the site.

Smart parking today is more than a necessary urban infrastructure element. Intelligent parking allows people to find empty spaces quickly and easily. It is a tool that would allow you to effortlessly get a clear idea of where you can find available parking spaces and how long each space is occupied.

Using low-cost sensors and smartphone-enabled payment systems, smart parking software can collect real-time traffic data, which can then be shared with operators, drivers and local authorities for efficient traffic and parking management. It also allows people to reserve parking in advance, or at least pinpoint their desired parking spot [18, 19]. An endto-end smart parking solution can help reduce car emissions in urban areas by reducing parking time and enable authorities to efficiently manage parking.

By implementing a parking management system, data analysis can better plan urban traffic, which will allow the city administration to manage its parking assets more efficiently. When the entire parking process is automated, the driver no longer needs to physically look for a place, buy a ticket and present it when leaving. However, this is not only about finding free parking spaces. Through the use of IoT and predictive analytics, smart parking initiatives can ultimately support the development of Smart Cities.

Smart cities can also implement dynamic parking rates where motorists pay for parking in real time. Thus, depending on the weather, traffic density, demand and changes in supply in real time, smart parking solutions can be used to maximize government revenues and optimize asset utilization.

Sensors, cameras and the IoT platform form the basic infrastructure for Smart Parking. To help cities improve the overall quality of life for city residents and visitors, a comprehensive smart parking solution is needed that provides:

1. Accurate vehicle detection in real time and locating available parking spaces significantly reducing the time spent on searches, providing drivers with accurate information on available parking spaces;

2. The ability to connect from the sensor to the cloud - this makes it easier to obtain realtime parking data that city planners and parking administration can use to reduce congestion; 
3. Parking apps for cities, parking owners and drivers - provide navigation to available parking and support mobile payments to streamline the parking process. Parking apps can also direct law enforcement towards offenders (for example, when parking in the wrong place), thereby helping to eliminate traffic congestion, as well as improve the efficiency of other city services such as public transport and garbage collection.

The creation of dedicated parking spaces began almost simultaneously with the appearance of the first cars. The number of cars is constantly increasing and modern technologies have been introduced to solve the rapidly growing problem of limited parking spaces.

The main area of development is "smart" parking sensors. Such sensors are built into the roadway at parking places and monitor the occupied or free space above them, transmitting data to the general system. Using a network of such sensors, a parking map is created, the state of which is transmitted to users on the streets using special screens or a mobile application [20].

There are many opportunities to increase the potential of smart parking sensors. One of the new concepts for closed parking lots is hinged sensors that additionally perform the function of guarding and monitoring the car.

The smart parking service is implemented through road sensors and smart displays that signal to motorists about free parking spaces. The benefits of this service are varied: less time spent parking means less $\mathrm{CO}_{2}$ emissions from the car, less traffic congestion, and better citizen satisfaction.

In addition, by using wireless technologies such as radio frequency identification (RFID) or Near Field Communication (NFC), an electronic parking permit verification system can be implemented in reserved slots or disabled slots, thus offering a better service to citizens who can legitimately use these slots, and effectively identify violations.

Another area of smart parking is the development and implementation of automated parking lots (most often multi-level), in which the actions of drivers are minimized. The driver enters a special platform / platform and gets out of the car. Then the platform itself transfers the car to a specially designated, reserved or free space, and informs the driver of its number. To get his vehicle, the driver must log in and enter this number on a special board or control panel, after which the platform will also lower the car to the site on its own (Figure 2) [21].

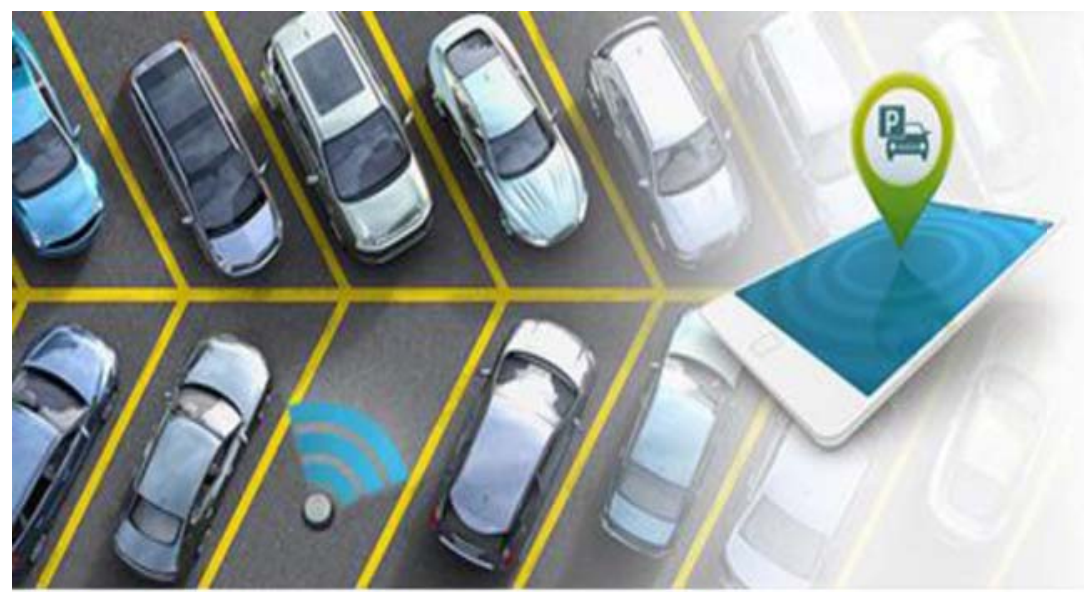

Fig. 2. A visual schematic representation of the smart parking business process. 
Figure 3 [21] shows a functional diagram of the smart parking system. The smart parking sensor is a digital magnetic device that detects the location of vehicles in parking areas.

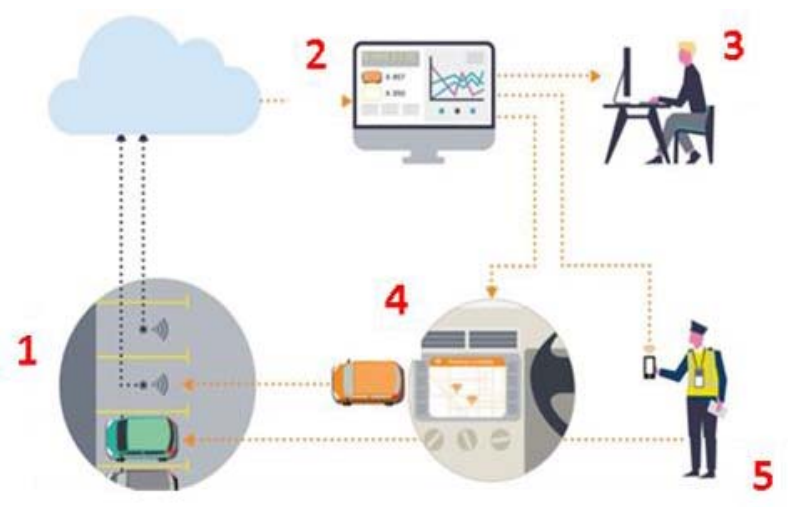

Fig. 3. Functional diagram of the smart parking system.

The sensor and radio transmitter are integrated in the parking space. Whether a seat is occupied or not is assessed (measured) by a sensor, and this information is transmitted to a special application running on the driver's mobile phone. Using the app, the driver can find the nearest free parking space.

Improved management of parking information, accurate accounting of the use / non-use of a parking space and reduction (minimization) of the time to find a temporary free space are important advantages of this technology $[18,19]$.

1. Sensors installed in the parking space monitor information online about the status (free / occupied) of the parking space, transmitting it to the cloud;

2. The cloud application enters the received information into the system. This information is analyzed to further optimize the parking planning procedure, generate notifications and fix the period (date);

3. The employee can monitor information and parking services;

4. Drivers receive information from the cloud and, thus, can easily find a parking space in the nearest area. They can also track activity, find out its cost and plan in advance where they would like to park the car;

5. The information is also transmitted to the street parking guards to validators to draw their attention to the parking area.

Currently, car parks that are closer to the city center tend to be more expensive than those on the outskirts. The dynamic parking management system can estimate the number of available free spaces and the level of air pollution in real time, and set the cost of parking according to the situation.

The main socio-economic advantages of introducing smart parking in relation to the infrastructures of smart cities: increase in revenues due to increased coverage and a system for issuing fines for violation of parking rules; additional income due to price changes based on analytical data; enhancing the productivity of law enforcement officials and empowering them through technology; an increase in the number of won disputes over parking fines; obtaining statistics and reports on employment and the nature of the use of parking spaces; cost-effective allocation of parking spaces [19-23].

The main socio-economic advantages of introducing smart parking for residents of smart cities: reduction of movement in a circle, which saves time and fuel; the ability to visualize the occupancy of parking spaces in real time; reducing the overall workload and improving the standard of living in general. 
The effectiveness of the implementation of an intelligent parking management system based on the Internet of Things technology in the socio-economic conditions of St. Petersburg can be confirmed by the following example. According to the data of the city center for the management of parking in St. Petersburg, the average load of paid parking lots in the Central District of St. Petersburg is $57.7 \%$.

The results of calculating the net present value and return on investment in the implementation of an intelligent parking management system based on the "Internet of Things" technology smart parking are as follows: net present value (NPV) - 678.7 million rubles; return on investment (ROI) significantly exceeds $100 \%$ and, thus, the project for the implementation of the software and hardware complex of the automated parking space management system "Smart Parking" is fully paid off.

\section{Conclusions}

The following should be noted as the main conclusions, recommendations and proposals formulated in the process of researching the scientific and practical foundations and business processes for the development of a modern smart city:

1. Smart parking, being an effective socio-economic toolkit of the Internet of Things, is an effective scientific and practical mechanism and, at the same time, the most effective business process for the development of modern smart cities.

2. The scientific novelty of the research is fully confirmed by the fact that Smart parking is a valuable social and economic resource, however, in most large cities of the world, the demand for parking significantly exceeds supply, which naturally actualizes the task of matching the needs of car owners.

3. The digital transformation of the economy provides government agencies with the ability to respond to current conditions based on the collected data. For example, a digital parking management platform can provide the flexibility to monitor and implement dynamic pricing that best suits a range of parking space requirements. Dynamic pricing means that the cost of parking changes based on availability and other factors.

4. In modern socio-economic conditions, there is no single agreed method for transforming cities, but intelligent technologies can significantly improve the quality of life of residents. From parking and security to pollution and social inclusion, by collecting, sharing and analyzing big data, smart city technologies will ensure the development of metropolitan areas in the future.

5. The scientific novelty and practical significance of the study lies in the argumentation of the fact that the Smart City of St. Petersburg strategy is immanently endowed with a number of unconditional transport and logistics advantages: the introduction of an intelligent transport business system will reduce the average time spent by a citizen by 22.5 times on my way; regression of energy consumption by urban infrastructure by $35-40 \%$; reduction of anthropogenic pressure on the environment by $20-40 \%$; a twofold increase in the economic efficiency of using public passenger transport; reduction of traffic congestion by $25-30 \%$.

\section{References}

1. T. Griffin, International Management Communication (Butterworth-Heinemann LTD, Oxford, 2018)

2. E. Berkowitz, R. Kerin, W. Rudelius, Management (Science, Boston, 2016)

3. A. Adams, Becoming of a society of network structures (Publishing house of the technical literature, Washington, 2015) 
4. I. Read, R. Read, Industry in the USA 7, 11-15 (2015)

5. N. Brown, Industry in the USA 5, 73-92 (2016)

6. K. Bread, Industry in the USA 2, 44-49 (2015)

7. D. North, A. North, Economy of USA: mentality, society, experience of the international cooperation (Science, Boston, 2018)

8. C. Water, NanoWeek 7, 96-108 (2016)

9. A. Williams, Business-angels of the USA (Science, Boston, 2016)

10. Ph. Kotler, W. Gregor, W. Rodggers, Management, economy, ecology 4, 22-45 (2015)

11. A. Green, NanoWeek 1, 65-81 (2016)

12. L. Kazanskaya, E. Palkina, 16th International Scientific Conference (University of Zilina, Rajecke Teplice, Slovak Republic, 2016) WOS:000393253800104

13. E. Balashova, I. Krasovskaya, E. Schislyaeva, F. Shamrai, IOP Conference Series: Materials Science and Engineering (2019) doi: 10.1088/1757-899X/497/1/012107

14. T. Roberts, N. Brown, Economy of business angels: the theory and practice (Publishing house of the technical literature, Washington, 2016)

15. S. Maydanova, I. Ilin, Proceedings of the 33rd International Business Information Management Association Conference, IBIMA 2019: Education Excellence and Innovation Management through Vision 2020, 8818-8833 (2019)

16. $\mathrm{Ph}$. Fisherman, K. Fisherman, Life cycle of the venture companies: science, finance, merges (Publishing house of the technical literature, Washington, 2015)

17. Transport in Russia - 2018. Statistical Book (Rosstat, Moscow, 2018)

18. Program "Digital Economy of the Russian Federation," approved by the Order of the Government of the Russian Federation on July 28. 2017. vol. 1632-r (2017)

19. Intelligent Transport Systems - Concept Note by the Inland Transport Committee of the Europe Economic Commission at the United Nations Organization, https://www.ipu.ru/sites/default/files/users/939/ECE\%20TRANS\%202016\%2020.pdf

20. DoD Policy Recommendations for The Internet of Things (IoT) December 2016 //https://www.hsdl.org/?abstract\&did=799676

21. Official site of "Parking St. Petersburg", https://parking.spb.ru/ru/pages/payment-onstreet/tariffs

22. Official site of the CD company - Telematika a.s, https://www.cdt.cz/en/smart-parking1282

23. T. Kagono, Work, Mobility and Participation: A Comparative Study of American and Japanese Industry (Butterworth-Heinemann LTD, Oxford, 2015) 